\title{
Scaling Up CSP: How Long Will It Take?
}

\author{
Johan Lilliestam ${ }^{1,2, a}$, Fengli Du ${ }^{3}$, Alina Gilmanova ${ }^{4}$, Mark Mehos $^{5}$, \\ Zhifeng Wang ${ }^{3,4}$, Richard Thonig ${ }^{1}$ \\ ${ }^{1}$ Institute for Advanced Sustainability Studies (IASS), Berliner Strasse 130, 14467 Potsdam, Germany \\ ${ }^{2}$ University of Potsdam, Germany \\ ${ }^{3}$ China Solar Thermal Alliance, Beijing, China \\ ${ }^{4}$ Key Laboratory of Solar Thermal Energy and Photovoltaic System, Institute of Electrical Engineering, Chinese \\ Academy of Sciences, Beijing, China \\ ${ }^{5}$ National Renewable Energy Laboratory, Golden (CO), USA \\ ${ }^{a}$ Corresponding author: johan.lilliestam@iass-potsdam.de
}

\begin{abstract}
Concentrating solar power (CSP) is one of the few scalable technologies capable of delivering dispatchable renewable power and, as such, many expect it to shoulder a significant share of system balancing in a renewable electricity future power by cheap, intermittent PV and wind power: the IEA, for example, projects 73 GW CSP by 2030 and several hundred GW by 2050 in its Net-Zero by 2050 pathway. In this paper, we assess how fast CSP can be expected to scale up and how long time it would take to get new, high-efficiency CSP technologies to market, based on observed trends and historical patterns. We find that to meaningfully contribute to net-zero pathways the CSP sector needs to reach and exceed the maximum historical annual growth rate of 30\%/year last seen between 2010-2014 and maintain it for at least two decades. Any CSP deployment in the 2020s will rely mostly on mature existing technologies, namely parabolic trough and molten-salt towers, but likely with adapted business models such as hybrid CSP-PV stations, combining the advantages of higher-cost dispatchability and low-cost intermittency. New third-generation CSP designs are unlikely to play a role in markets during the 2020s, as they are still at or before the pilot stage and, judging from past pilot-to-market cycles for CSP, they will likely not be ready for market deployment before 2030. CSP can contribute to low-cost zero-emission energy systems by 2050, but to make that happen, at the scale foreseen in current energy models, ambitious technology-specific policy support is necessary, as soon as possible and in several countries.
\end{abstract}

\section{INTRODUCTION}

In recent months, countries around the world have set new, strict climate targets for 2030 and climate-neutrality targets for mid-century $[1,2]$. To meet these targets, many countries will take the leap into renewables-based systems during the coming decades. In most countries, the bulk of the future electricity supply will be based on solar PV and wind power: these options today often supply the cheapest kilowatt-hours of all technologies [3], but both are intermittent and generate power largely independently of the demand. For renewable power systems to remain stable, technologies to balance intermittent generation are necessary. This includes infrastructure, prominently transmission grids, storage options such as batteries [4,5], and dispatchable renewable generation [6]. Among the latter, concentrating solar power (CSP) is one key option.

Concentrating solar power can be a critical component of zero-carbon power systems, serving as an enabler of accelerated deployment of cheaper but intermittent power [7]. As CSP is one of the cheapest options for energy storage [8, 9], it could carry a significant part of the renewable balancing of fluctuating renewables in sunny regions [7]. Several studies suggest that CSP has an important role to play in a zero-carbon power system: the IEA's Net-Zero by 2050 report, for example, suggests that the global CSP fleet should grow to $73 \mathrm{GW}$ by 2030 and $281 \mathrm{GW}$ by 2040 [10]. Similarly, IRENA projects several hundred GW CSP by 2050, to help balance a global fleet of $8500 \mathrm{GW}$ of PV and $6000 \mathrm{GW}$ of wind power [11]. This indicates that CSP could fill a gap that PV and wind power cannot, namely that of dispatchable renewable power on demand. But even at this modest scale, compared to PV and wind power, 
CSP would need to grow very fast: for the IEA projection, the current global CSP fleet of some $6 \mathrm{GW}$ would need to increase by more than a factor of 10 in less than a decade.

Currently, no such CSP expansion is in sight - indeed, as costs are comparatively high, CSP projects remain dependent on technology specific policy support, but except two running multi-technology auctions with minor CSP components in China [12,13], there is presently not a single support scheme open to new CSP projects as countries have terminated their support schemes or stopped auctioned new CSP capacity [14]. Consequently, no new CSP project has started construction outside China since 2018. To alleviate the need for subsidies, large R\&D efforts seek to reduce the cost of CSP, both to improve the technology itself and to remain in the race for policy support and market shares with the renewable power competitors $[15,16]$.

In this paper, we investigate how fast CSP technologies can be expected to be scaled up, assessing both how fast new advanced CSP technologies can be expected at commercial scale and what it would take to meet the ambitious expectations for CSP deployment by 2030 and beyond. To do this, we investigate past and current growth patterns, including both general supply chains and innovation sequences for advanced CSP technologies from pilot to established commercial-scale deployment. We find that the new technologies under development are highly unlikely to enter the market by 2030, so that any near-term CSP deployment will be based on existing technologies; achieving a CSP expansion of the scale proposed by the IEA is hardly feasible, but if the policy and market setting is conducive, a global expansion of several GW per year appears within reach during the 2020s.

\section{THEORY AND BACKGROUND}

The diffusion of a new technology typically runs in three distinct phases, giving rise to an s-shaped deployment curve $[17,18]$. Initially, in the formative phase, the new technology grows slowly and often erratically, as deployment is characterised by a high dependency on special market niches, such as policy support schemes, and by considerable uncertainty about the future potential and performance of the technology. Typically, technologies grow only in one or a few national markets during the formative phase, nursed by specific niches or support systems, and these pioneer markets are often the seed of the subsequently dominant industries [19, 20]. Although the technology hardly makes a dent in national energy or emissions statistics, it develops "below the radar", through the slow processes of technological development that enable the later diffusion [21]. Estimates of the duration of the formative phase differ very strongly across sectors and assessment methods, but is typically several decades, with shorter durations for innovations closely replacing incumbent technologies [22].

In the growth phase, the innovation starts to spread more widely, as the technology improves. When this happens, the technology diffusion accelerates strongly, as the regime starts changing, and the deployment triggers a process of increasing returns - a virtuous circle of decreasing costs and increasing deployment. Typically, the technology moves from the initial lead market to a growing number of countries, from core to peripheral countries, leading to faster global deployment and technological maturation [18,23]. Cherp et al. place the breaking point between formative and growth phases at $1 \%$ of the market, and note that the phase shift can be slow: for wind power, it took 30 years (19892019) after wind power reached $1 \%$ of generation in the first country (Denmark) until a majority of countries also reached 1\%; for solar PV, this took 10 years, from 2009 (Spain and Germany) to 2019 [17].

Eventually, growth slows down, as demand for the specific technology is saturated, and marginal costs of deployment start increasing, arising from diverse issues such as resource depletion, infrastructure congestion or political opposition to further expansion. In this phase, the market share stagnates, until it eventually starts declining, driven by market forces or by deliberate decline policies [24].

Currently, CSP is in the formative stage and commercial-scale CSP has been deployed in only 10 countries (Tab. 1). Spain was the home to the initial CSP surge and - although its CSP support was cancelled almost 10 years ago is still the home of the globally dominant CSP companies [14]. There is still no dominant design, indicating that the CSP sector is still searching for the setting and main technological configuration with which it will enter the growth phase. Growth patterns have been highly irregular and characterised by stop-and-go of policy support, and consequently the centre of deployment has shifted, from Spain (2007-2013) to the US (2013-2015), to China (20182021), with single stations constructed in other countries, notably Morocco, UAE and South Africa. This irregular growth has also affected the cost development, with cost increases accompanying the lull in deployment in 2015-2017, and likely adding to the political unattractiveness of CSP support. Today, CSP has a negligible market share in all countries except Spain and Morocco (Tab. 1). As the expansion in Spain has stopped, and the Moroccan power market is small - so that three CSP stations lead to this high market share - it is clear that CSP is still in its formative stage, globally and in every country [20]. 
TABLE 1: Expected CSP generation (all stations >10 MW operational in July 2021, excluding ISCCs) as share of national power supply (2020) in the countries with known CSP generation. Rounded. Sources: [25-28].

\begin{tabular}{lccccc}
\hline & $\begin{array}{c}\text { Expected CSP } \\
\text { generation (GWh/year) }\end{array}$ & $\begin{array}{c}\text { Electricity supply } \\
\text { (TWh/year) }\end{array}$ & CSP share & Of which trough & Of which tower \\
\hline Spain & 6087 & 255.8 & $\mathbf{2 . 4 \%}$ & $2.3 \%$ & $0.1 \%$ \\
US & 4443 & 4286.6 & $\mathbf{0 . 1 \%}$ & $0.1 \%$ & $0.04 \%$ \\
China & 2066 & 7779.1 & $\mathbf{0 . 0 3 \%}$ & $0.01 \%$ & $0.02 \%$ \\
South Africa & 2029 & 239.5 & $\mathbf{0 . 8 \%}$ & $0.7 \%$ & $0.1 \%$ \\
Morocco & 1470 & 38.2 & $\mathbf{3 . 9 \%}$ & $2.5 \%$ & $1.3 \%$ \\
Chile & 950 & 620.1 & $\mathbf{0 . 2 \%}$ & 0 & $0.2 \%$ \\
Israel & 735 & 74.3 & $\mathbf{1 . 0 \%}$ & $0.6 \%$ & $0.4 \%$ \\
UAE & 210 & 138.4 & $\mathbf{0 . 2 \%}$ & $0.2 \%$ & 0 \\
\hline
\end{tabular}

To overcome this cost disadvantage and improve both the political and economic attractiveness of CSP, a new generation of CSP technologies, capable of operating at higher temperatures, is the focus of ongoing R\&D efforts [29]. Different projects exist for different types of particle receivers, high-temperature liquids and gases [16, 30]. Because plants using higher working temperatures are thermodynamically more efficient, such technologies may become cheaper than existing configurations, potentially leading to a step-change in the cost trajectory of CSP [31]. These advanced CSP technologies are, however, still immature and must first prove their usefulness at the single-MW scale before they may become candidates for commercial-scale deployment [32].

\section{METHOD}

Our investigation rests on the analysis of past and current trends in the CSP sector. To this end, we have merged the CSP project databases (NREL/SolarPACES and csp.guru), and expanded the dataset with more detailed categories. The resulting dataset, validated for 1 July 2021, is freely accessible at www.csp.guru [28].

First, we assess past market and supply chain growth to identify how fast the CSP industry has been able to scale up deployment of existing technologies in the past. From this analysis, we provide an upper range of feasible midterm market sizes based on existing station designs.

Second, we explore which technologies can be expected to shoulder this task, by identifying past growth and deployment. For this, we investigate the development patterns and time requirements for new designs, from pilot to first-of-a-kind (FOAK) commercial-scale station, which is when a design is demonstrated to work at scale, and secondof-a-kind (SOAK), demonstrating a mature design ready for large-scale deployment. From this analysis, we infer when which advanced CSP technologies can be expected to reach market deployment maturity.

\section{RESULTS}

\section{Current Market Dynamics and Near-Term Deployment Projections}

The global CSP market has strongly fluctuated year-on-year over the last 15 years. During the Spanish and US deployment phases in 2007-2014, with favourable and predictable policy support, the market grew by 20-30\%/year (Fig. 1). From its historical maximum of 34\%/year in 2008 and 2009, the yearly average growth rate steadily decreased and has been 5-10\%/year in the last 5 years, both as the cumulated fleet grew but especially as the deployment pace fell - by 2017 to only $25 \%$ of the peak deployment in 2014 . Whereas parabolic troughs have strongly dominated deployment in the past, the market changed in the last 5 years and today the more efficient (due to their higher working temperature) towers have about the same market share as troughs (Fig. 1Error! Reference source not found.). The absolute deployment pace (3-year average) of CSP decreased to 100-200 MW/year for both troughs and towers and reached $0.5 \mathrm{GW} /$ year only once in the 5-year period (in 2019). 2021 and 2022 have a total of $1.1 \mathrm{GW}$ of CSP scheduled for completion suggesting a cumulative installed capacity of $7.6 \mathrm{GW}$ at the end of 2022. At the present deployment pace of $0.5 \mathrm{GW} /$ year, we would expect about another $4 \mathrm{GW}$ added capacity by 2030 bringing the global CSP fleet to only $11.6 \mathrm{GW}$, far short of the $73 \mathrm{GW}$ expected by the IEA. Nevertheless, we observe that experienced supply chains and component suppliers exist for both segments, suggesting that scale-up of both towers and troughs is feasible in the short term [14]. 

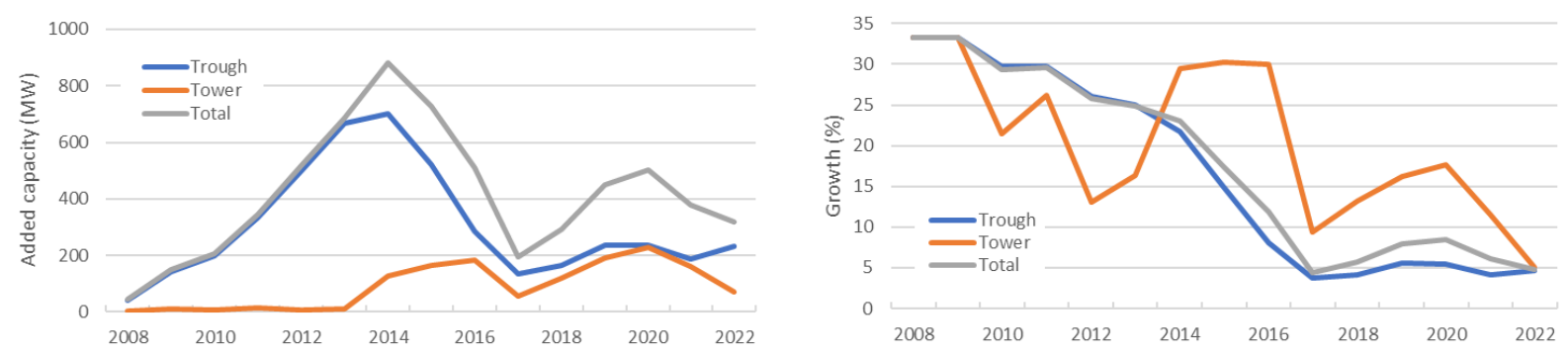

FIGURE 1: 3-year running average of deployment (left) and cumulative global CSP system growth (right), 2008-2022. Operating projects (-June 2021) and under construction planned for completion (July 2021-Dec. 2022). Source: CSP.guru [28].

Assuming that the CSP supply chains can reach and - very optimistically - maintain the maximum observed growth of 30\%/year from the $7.6 \mathrm{GW}$ expected at the end of 2022 (it is unlikely that any station that is not yet known will be built in less than a year), the global CSP would grow to $63 \mathrm{GW}$ by 2030, with $14 \mathrm{GW}$ added in the last year alone (Fig. 2). Hence, even under the most optimistic conditions of massive and immediate deployment, CSP will still fall short of the $73 \mathrm{GW}$ projection. Thus, unprecedented growth exceeding an annual growth rate of 30\%/year for the rest of the 2020s is needed to meet the IEA goal. This also puts existing targets, such as the Spanish target of 5 GW new CSP by 2030 [14] into perspective: deployment such as expected by the IEA would require the Spanish deployment ambition implemented immediately, in Spain and in 12 other countries. The more realistic 10-20\% growth would lead to 16-29 GW by 2030, but even for such growth, new support schemes in multiple countries are necessary.

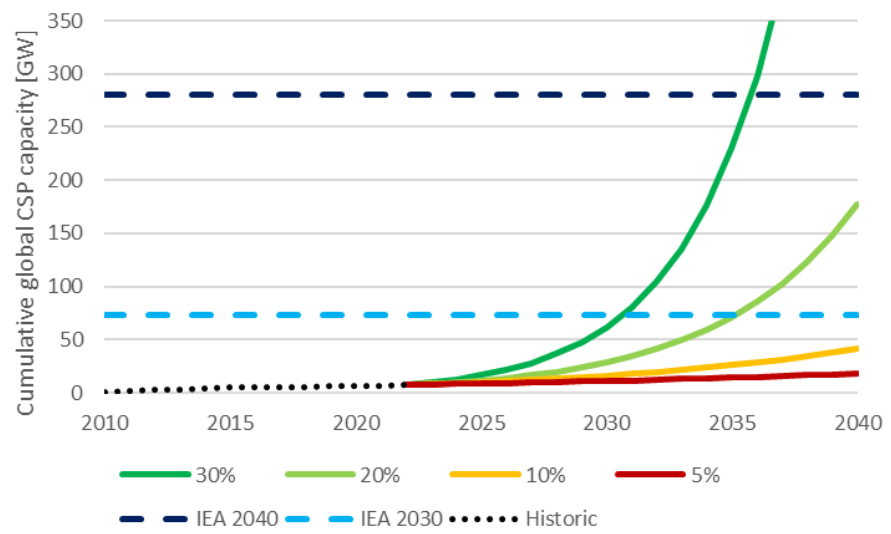

FIGURE 2: Projections of different cumulative annual growth rate to reach IRENA scenarios (left) and the associated yearly capacity additions (right). Own elaboration based on CSP.guru [28].

This shows that for CSP to play the role foreseen for example by the IEA, an unprecedented sectoral growth, exceeding 30\%/year, starting immediately in many countries and sustained for the whole decade, is necessary. This is highly unlikely given the current absence of policy support for new projects. If we take additional complexities such as the lead-times for negotiations in governments, implementation in bureaucracies, project development in the industry, auctioning, financing, etc. into account, it would be a substantial achievement to reach a multi-GW global CSP project pipeline in the second half of the decade. In sum, our results suggest that the expectations of IEA or IRENA for CSP to become a major global electricity source in the 2020s are unrealistic - more feasible expectations, which still requires immediate large-scale support, point to a fleet of $15-30 \mathrm{GW}$ by 2030 , which is less than the current monthly additions of PV and wind power, respectively. If the support comes quickly and at scale, CSP may yet emerge as a regionally important source of dispatchable renewable power in the 2020s, exceeding a few percent of the power mix and possibly stepping out of its formative stage in smaller power systems, such as Spain or a MENA country, but hardly in larger markets and or in the global perspective. 


\section{Reducing the Cost of Commercial-Scale Projects to Accelerate Deployment}

High costs remain an important barrier for CSP deployment [33], although costs have decreased by some $60 \%$ in the last decade (Fig. 3). In the last 5 years (2016-2021), towers and troughs have developed at similar costs - both with an average levelised cost of electricity (LCOE) ${ }^{1}$ of about USD0.2/kWh outside China and USD0.1/kWh in China [28]. As the tower fleet is smaller and more diverse than the trough fleet, towers are likely less "learned out" and may hold a larger potential for future cost reductions.

Among the recently finished stations and under construction, we note that several projects reduce costs through a shift to hybrid CSP-PV stations [34-36]: developers include cheap but intermittent PV in a CSP power purchase agreement (PPA), letting the PV component generate power during day and the CSP component during low-sun conditions and after sunset. This strategy exists in both Cerro Dominador (2021, Chile) and Noor Energy 1 (under construction, Dubai); it is also proposed in the bids for the Likana station (Chile) and - with a deeper PV-hybridisation strategy - in Midelt (Morocco), both of which are projects under development but not under construction and may not be realised. This suggests that CSP-PV hybrid stations, relying on currently available trough or tower technology, are emerging as a dominant approach to reduce costs for dispatchable solar power. The increasing number of such projects demonstrates its feasibility: CSP-PV hybrid designs are currently being tested and will be, assuming they deliver as promised, ready for commercial deployment in the 2020s.

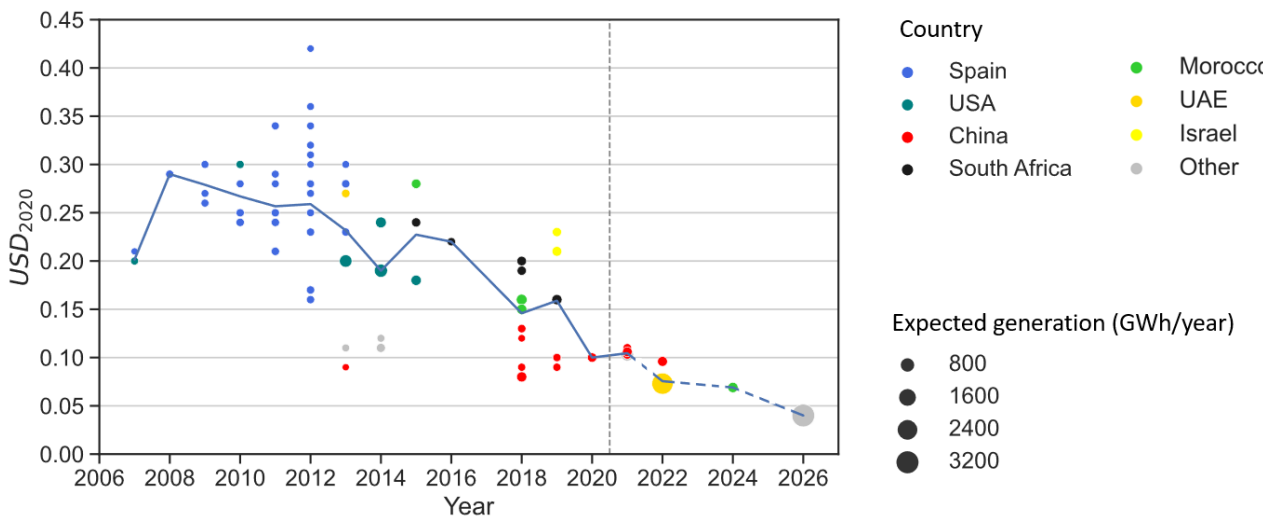

FIGURE 3. average yearly LCOE of CSP stations becoming operational (2007-July 2021), and hybrid stations planned for completion July 2021-Dec. 2022, and the bids for proposed projects post-2022 (auction bid Likana, awarded PPAs Noor Energy 1 and Midelt). Source: [28].

Another route for cost decrease is through technology push of new lower-cost CSP designs. Currently, several high-temperature pilot projects are under construction in China, the US, Mexico and Australia towards this end. These technologies, including particle receivers and supercritical $\mathrm{CO}_{2}$ Brayton power cycles, promise higher efficiencies and novel applications [37] that may result in lower costs, but are currently at or before the pilot stage. In 2021, for example, Sandia Labs was awarded a grant for a particle receiver pilot station at the existing test site, for $6 \mathrm{MW}_{\text {th }}$ with $6 \mathrm{MWh}$ storage. The developers aim for demonstrating the design over the next 5 years, if supercritical $\mathrm{CO}_{2}$ power cycle units are ready for commercial-scale deployment by then [38, 39].

TABLE 2. Non-exclusive list of (summer 2021) CSP pilot projects in operation or under construction. Sources: project websites.

\begin{tabular}{lcr}
\hline Project & What & \multicolumn{1}{c}{ Novelty } \\
\hline Vast Solar, Australia & Tower, 1.1 MW & Sodium receiver (up to $\left.900^{\circ} \mathrm{C}\right) ; 1.1 \mathrm{MW}$, plans for 50 MW \\
EuroPaTMos, EU & Trough $(<$ pilot-scale) & Molten salt trough receiver R\&D \\
Heliogen, USA & Heat; tower & AI-Heliostats, heat for mining with Riotinto \\
Sandia, USA & Tower, particle receiver & $>700^{\circ} \mathrm{C}$ particle tower receiver; Gen3 Particle Pilot Plant \\
HiFlex, Italy & Tower, particle receiver & Particle receiver, with electric heater; $2.5 \mathrm{MW}_{\text {th }} 1000^{\circ} \mathrm{C}$ \\
Shouhang, China & $\mathrm{s}-\mathrm{CO}_{2}$ tower & Conversion of existing CSP demo to supercritical $\mathrm{CO}_{2}$ \\
Synhelion, Mexico & Heat \& fuel; tower & New receiver, $1500^{\circ} \mathrm{C}$ \\
\hline
\end{tabular}

\footnotetext{
${ }^{1} 25$ years economic life; $5 \%$ WACC.
} 


\section{Commercialising Third-Generation CSP}

In the past, CSP has gone through the innovation chain stages $[17,40]$ from lab to demonstration projects to precommercial scale pilot projects, before stepping into the market with commercial-scale projects [41, 42]. Our results suggest that going from demonstration to commercial-scale FOAK deployment in less than 10 years is possible, but development times have generally been longer. Once the FOAK has proven the feasibility of a CSP design, rapid market scale-up is possible if the policy and market environment support further CSP deployment. Today, the trough segment is the most mature, and several companies have well-proven SOAK designs. The tower segment still mainly sees FOAK designs, in single projects of each type, but seems to be on the verge of large-scale deployment. The market has been diverse and has, typical for this stage of technology development, seen many new entrants and exits including both mergers and bankruptcies. Despite this diversity, the development of most of the current CSP designs can be traced back to a handful of early demonstration and R\&D projects (Tab. 3).

For commercial scale deployment, parabolic trough has been strongly dominant, with $75 \%$ of the global fleet [28]. In this segment, technological diversity is relatively low, with much cross-transfer of experience and technological knowhow through mergers and acquisions. Initial experience for the trough expansion was gained in the SEGS stations in California, constructed by Luz in the 1980s and mostly still operational today. Most leading companies are, through acquisions, movement of workers, or co-development of projects, connected to SEGS in various ways [43]. The EuroTrough project was a technological milestone for the European companies that still dominate the trough market, e.g. Abengoa and Schlaich Bergermann, and included CSP pioneers such as Solel [44]; through this project, considerable experience transfer from SEGS to the European trough champions can be assumed.

In the tower segment, the Solar project, resulting in the SolarOne (1981) tower, which later developed into the molten salt tower SolarTwo (1995), was the start of the salt towers technology. At the pilot stage, many of the companies that were to eventually build the tower stations operational today stepped in, prominently SENER (through Torresol) in the Gemasolar project (initially called SolarTres) and Abengoa in CRS Sales; the experiences gained in these projects supported the construction and operation of Noor III and Cerro Dominador projects [45, 46]. More recently, the Chinese tower champions Shouhang and Cosin Solar (previously: Supcon), drawing on experiences from the Badaling demonstration plant, designed their own pilot plants at Dunhuang and Delingha, both of which developed into the commercial-scale projects at the same locations. BrightSource, the only non-Chinese tower company with a SOAK station, draws on experiences of the SEDC pilot project in Israel, which generated experiences with this technology for the Ivanpah and Ashalim stations. As the molten salt tower segment is less mature than the trough segment, but still projects claim similar costs, the near-term development will likely show falling tower costs, placing this configuration as the main CSP technology, assuming that further CSP deployment support is implemented.

For Fresnel stations, the empirical material is thin, because there are very few stations; in the few cases with data, lead times appear relatively short.

TABLE 3: Sequences of demonstration and pilot projects leading to FOAK and SOAK CSP stations. Sources: [28] and project websites. Not all demo/pilot projects and involved companies are displayed.

\begin{tabular}{|c|c|c|c|c|c|}
\hline Tech. & Company & Demonstration & Pilot 5-20 MW & FOAK $\geq 30 \mathrm{MW}$ & SOAK \\
\hline Trough & $\begin{array}{l}\text { Luz } \\
\text { Abengoa } \\
\text { Sener } \\
\text { Acciona, } \\
\text { SBP, TSK }\end{array}$ & $\begin{array}{l}\text { n.k. } \\
2000 \text { EuroTrough } \\
\text { n.k. } \\
\text { n.k. } \\
2000 \text { EuroTrough }\end{array}$ & $\begin{array}{l}\text { 1984 SEGS } 1 \\
\text { n.k. } \\
\text { n.k } \\
\text { n.k. } \\
\text { n.k. }\end{array}$ & $\begin{array}{l}1985 \text { SEGS 2-7 } \\
2009 \text { Solnova } 1 \\
2010 \text { Extresol } 1 \\
2007 \text { Nevada Solar } 1 \\
2008 \text { Andasol } 1\end{array}$ & $\begin{array}{l}1989 \text { SEGS 8-9 } \\
2009 \text { Solnova } 3 \\
2011 \text { Extresol } 2 \\
2009 \text { La Risca } \\
2009 \text { Andasol } 2 \\
\end{array}$ \\
\hline Tower & $\begin{array}{l}\text { Abengoa (steam) } \\
\text { Abengoa (salt) } \\
\text { Sener } \\
\text { SolarReserve } \\
\text { Brights. (steam) } \\
\text { Brights. (salt) } \\
\text { Supcon } \\
\text { Shouhang } \\
\end{array}$ & $\begin{array}{l}1995 \text { S.One/Two } \\
1995 \text { SolarTwo } \\
1995 \text { SolarTwo } \\
\text { 1995 SolarTwo } \\
\text { n.k. } \\
\text { n.k. } \\
\text { 2012 Badaling-1 } \\
\text { 2012 Badaling-1 }\end{array}$ & $\begin{array}{l}2007 \text { PS10,20 } \\
2012 \text { CRS Sales } \\
2011 \text { Gemasolar } \\
\text { n.k. } \\
\text { 2008 SEDC } \\
\text { n.k. } \\
\text { 2013 Delingha-10 } \\
\text { 2016 Dunhuang-10 }\end{array}$ & $\begin{array}{l}2018 \text { Khi Solar } \\
2021 \text { Cerro Dominador } \\
2018 \text { Noor III } \\
\text { 2015 Crescent Dunes } \\
\text { 2014 Ivanpah } \\
2022 \text { Noor Energy } 1 \\
\text { 2018 Delingha-50 } \\
\text { 2018 Dunhuang-100 }\end{array}$ & $\begin{array}{l}\text { N/A } \\
\text { N/A } \\
\text { N/A } \\
\text { N/A } \\
\text { 2019 Ashalim } \\
\text { N/A } \\
\text { 2022 Delingha135 } \\
\text { 2022 Yumen-100 }\end{array}$ \\
\hline snel & $\begin{array}{l}\text { Novatec } \\
\text { Areva Solar } \\
\text { Lanzhou D. }\end{array}$ & $\begin{array}{l}\text { n.k. } \\
\text { 2005 Ausra } \\
\text { n.k. }\end{array}$ & $\begin{array}{l}2009 \text { P. Errado } 1 \\
\text { n.k. } \\
2016 \text { Dunhuang-15 }\end{array}$ & $\begin{array}{l}2012 \text { Puerto Errado } 2 \\
\text { 2014 Dhursar } \\
\text { 2019 Dunhuang-50 }\end{array}$ & $\begin{array}{l}\text { N/A } \\
\text { N/A } \\
\text { N/A }\end{array}$ \\
\hline
\end{tabular}

n.k: not known. N/A: not applicable/does not exist. 
These demo-to-market routes mark the current technological frontier of commercially deployed CSP. They are the result of long research and development processes, tracing back to the 1980s and 1990s. The pilot-to-FOAK sequences are about a decade, with longer times in Europe, very likely connected to the absence of a market and support scheme prior to 2007. We observe shorter times in China - which is expected, as these stations draw on more mature technology developed in other R\&D and pilot projects and found a market created by the feed-in tariff implemented in 2016 directly after completion of the pilot towers. Whereas the initial delay from SolarOne and SolarTwo to FOAK commercial-scale towers is mainly explained by the absence of a support scheme under which commercial-scale towers could be built, it is also notable that the pure construction time of the FOAK stations has sometimes been long (e.g. 4 years for Crescent Dunes) [28].

The scale-up times from demonstration/pilot to FOAK appear to have been largely determined by the market situation. In California, construction of SEGS II, the FOAK based on the same design as SEGS I, was built in parallel to the first station under the financially beneficial PURPA scheme, and the expansion of the SEGS stations ended abruptly as the remuneration under PURPA changed, and the developer Luz went bankrupt [47]. In Spain, following the successful development of the EuroTrough, no commercial trough stations were built until the feed-in tariff was implemented in 2007. Hence, there is little to learn regarding timing from parabolic troughs, except that sufficient policy support was necessary for any commercial-scale development to happen at all. Because there are no trough stations with Chinese domestic designs - all at least partially use European technology - we have no insight into the speed of demonstration-to-FOAK sequences in China. A characteristic of the Spanish CSP expansion, however, is the replication of station designs: as soon as the feed-in tariff was implemented and FOAK stations in place, the SOAK stations followed quickly, establishing two dominant types of trough stations, with either zero or 7.5 hours of thermal storage, which today make up almost all of the 50 Spanish CSP stations [48]. This suggests that for CSP, just as has been shown for other complex technologies [49], the bottleneck to market breakthrough lies especially in the FOAK: once a well-functioning design has been proven, the scale-up of supply chains for that design can be rapid.

Applying these lessons to novel CSP designs, we suggest that, as with previous CSP innovations, it is not possible to say which of the tested technologies will perform, which ones may be feasible for commercial deployment, and how far costs will come down. There are many promising configurations, but judging from past lead times, and on statements from the developers themselves, all designs are at least a decade away from FOAK market introduction. The construction time of a third-generation CSP station can be expected to be several years, suggesting that a hightemperature FOAK starting operation in 2030 need to start construction around 2027, leaving 5 years to demonstrate feasibility, gain experiences in a pilot project and plan and design a commercial-scale installation. Whereas this is likely possible in the technical sense, under ideal conditions, the history of CSP suggests that such new hightemperature CSP stations are not ready for mentionable commercial-scale deployment in the 2020s - but may well be ready during the early 2030s. Therefore, any appreciable commercial CSP deployment in the next 10 years is likely going to be existing technologies.

\section{DISCUSSION AND CONCLUSIONS}

Our results show that with current policies CSP is unlikely to become a globally important contribution to power system balancing in the next decade. Even if the CSP sector could manage to its reach historically highest observed growth rate of 30\% fleet growth per year and sustain it throughout the entire 2020s, the global fleet would be $62 \mathrm{GW}$ in 2030, with a maximum deployment speed of $14 \mathrm{GW} / y e a r$, and thus far below IEA and IRENA projections. Whereas such deployment would be a huge leap ahead for CSP - 10 times the existing fleet in 2021 - even 14 GW/year is just above $10 \%$ of the deployment pace of PV and wind power, respectively. This means that CSP will remain a niche technology in the global perspective throughout the 2020s, and very likely also in the large power systems such as the US and China. CSP may however play a substantial role in specific smaller systems, such as Spain, Israel, Morocco, Chile or South Africa, already in the next decade, if deployment there is restarted and strongly increased through technology-specific support adequately valuing dispatchable power [50-52].

New CSP technologies, such as particle receivers and supercritical $\mathrm{CO}_{2}$ cycles, hold promise of higher efficiency and lower costs in the future, but they are currently at the pilot stage and are unlikely to be available for substantial commercial-scale deployment in the 2020s. For new, more efficient CSP technologies to enter the market, near-term demonstration projects followed by commercial-scale FOAKs are needed, first to prove the technology and then to show that the system works at scale to make projects bankable. Any large-scale CSP deployment in the next decade, however, will happen with existing technologies, both the recently commercialised molten-salt towers and the more proven parabolic troughs. Especially in the tower segment, economies of scale have barely been realised yet and a 
large future project pipeline could trigger substantial cost reductions from technological learning, especially if lessons from past failures can be internalised [53]. The PV-hybrid CSP stations observed in recent commercial projects and proposals have proven to be a reliable way to push down power costs in the short-term without radical redesign of the CSP technology [35, 54, 55]. Such organisational, rather than technical, innovations are a promising approach to reduce the cost of solar "baseload" in the short to medium term, and could also increase in prominence in upcoming PV plus storage deployment.

Our findings have two important implications. First, in the near to medium term, most CSP cost reductions will likely not come mainly through R\&D but from deployment, through organisational improvements such as multitechnology PPAs and from technological learning in existing CSP technologies, especially in towers. Research and development of new CSP technologies is important in the longer term, to develop new, high-efficiency designs - and significant spillovers across concentrating solar technologies are possible [37], but not to decrease costs rapidly or to increase deployment in the next decade.

Second, in order to have CSP deployment at a scale relevant for deep decarbonisation in the first half of this century, it is critical that new CSP deployment support programs are implemented, rapidly and in as many countries as possible, to generate a new project pipeline and maintain and quickly scale up the existing but struggling CSP industry. Such support needs to be technology-specific enough to trigger CSP construction, but technology-neutral enough to allow for experimentation and innovation among developers. Hybridisation is a big promise for short-term cost reduction, but supporting it requires stepping away from current policy support paradigms, both because such a policy would not support one but several technologies - a type of policy that does not exist yet - and because it would adopt the dynamic, long-term cost-reducing perspective that characterised the feed-in tariffs of the past but not the short-term cost-minimisation that dominates current renewables policy.

As in the past, current CSP deployment projections are exaggerated and detached from the implemented policies. Grand visions and bold projections like the Desertec project have proven to be powerful tools to trigger immediate interest in a technology, but the political fallout of raising high hopes and failing them also proved dramatic and contributed to making CSP a political non-starter, at least in Europe, for many years [56]. Concentrating solar power may prove to be an essential technology for the energy transition, in the long run. Because CSP still depends on policy support, it is essential that CSP increases its political attractiveness - and for that, exceeding ambitious but achievable targets may be better than raising unattainable expectations. Rome wasn't built in a day, and neither will CSP.

\section{ACKNOWLEDGEMENTS}

This work was supported by a research grant from SolarPACES (OpenCSP project).

\section{REFERENCES}

1. White House. President Biden sets 2030 greenhouse gas pollution reduction target. 2021 2021.09.12]; Available from: https://bit.ly/3EauJTj.

2. EC, Amended proposal for a European Climate Law. COM(2020)563 final. 2020, European Commission (EC): Brussels.

3. IRENA, Renewable power generation costs in 2020. 2021, IRENA: Abu Dhabi.

4. Schmidt, O., et al., The future cost of electrical energy storage based on experience rates. Nature Energy, 2017. 2: p. 17110.

5. Beuse, M., B. Steffen, and T.S. Schmidt, Projecting the competition between energy-storage technologies in the electricity sector. Joule, 2020. 4(10): p. 2162-2184.

6. Tröndle, T., et al., Trade-offs between geographic scale, cost, and system design for fully renewable electricity in Europe. Joule, 2020.

7. Resch, G., et al., Deep decarbonization of the European power sector calls for dispatchable CSP. AIP Press, in press.

8. Schöniger, F., et al., Making the sun shine at night: comparing concentrated solar power and photovoltaics with storage. Energy Sources, Part B: Economics, planning and policy, 2021. 16(1): p. 55-74.

9. World Bank, Concentrating solar power. Clean power on demand 24/7. 2021, World Bank: Washington.

10. IEA, Net zero by 2050. 2021, International Energy Agency (IEA): Paris.

11. IRENA, World energy transitions outlook: 1.5 degrees pathway. 2021, International Renewable Energy Agency (IRENA): Abu Dhabi. 
12. HeliosCSP. 3*100MW concentrated solar power auctions announced in China. 2021 2021.09.26]; Available from: https://helioscsp.com/3100mw-concentrated-solar-power-auctions-announced-in-china/.

13. CSP Focus. Another 2*100MW CSP announced in Northeast China. 2021 2021.09.26]; Available from: http://www.cspfocus.cn/en/market/detail 4697.htm.

14. Lilliestam, J., et al., The near-to mid-term outlook for concentrating solar power: mostly cloudy, chance of sun. Energy Sources, Part B: Economics, planning and policy, 2021. 16(1): p. 23-41.

15. DOE, Solar energy technologies office multi-year program plan. 2021, US Department of Energy (DOE): Washington, D.C.

16. EC, The Strategic Energy Technology (SET) Plan. 2019, European Commission: Brussels.

17. Cherp, A., et al., National growth dynamics of wind and solar power compared to the growth required for global climate targets. Nature Energy, 2021. 6(July): p. 742-754.

18. Victor, D., F. Geels, and S. Sharp, Accelerating the low carbon transition. 2019, Energy Transitions Commission: London.

19. Beise, M. and K. Rennings, Lead markets and regulation: a framework for analyzing the international diffusion of environmental innovations. Ecological Economics, 2005. 52: p. 5-17.

20. Gosens, J., A. Gilmanova, and J. Lilliestam, Windows of opportunity for catching up in formative clean-tech sectors and the rise of China in concentrated solar power. EIST, 2021. 39: p. 86-106.

21. Hanna, R. and D. Victor, Marking the decarbonization revolutions. Nature Energy, 2021. 6: p. $568-571$.

22. Bento, N. and C. Wilson, Measuring the duration of formative phases for energy technologies. Environmental Innovation and Societal Transitions, 2016. 21(December): p. 95-112.

23. Markard, J., The next phase of the energy transition and its implications for research and policy. Nature Energy, 2018. 3(August): p. 628-633.

24. Rosenbloom, D. and A. Rinscheid, Deliberate decline: an emerging frontier for the study and practice of decarbonisation. WIREs Climate Change, 2020: p. e669.

25. BP, BP statistical review of world energy 2020. 2021, BP: London.

26. HeliosCSP. Cerro Dominador concentrated solar power plant milestones. 2018 2021.08.23]; Available from: https://bit.ly/3AodQT3.

27. EVwind. Chile's Cerro Dominador concentrated solar power signs PPA with power distributor Saesa. 2020 2021.08.23]; Available from: https://bit.ly/3k6tSLl.

28. Lilliestam, J., et al., CSP.guru (Version 2021-07-01) [Data set]. . 2021: IASS Potsdam, http://doi.org/10.5281/zenodo.5094290.

29. Mehos, M., et al., On the path to SunShot. 2016, NREL: Golden.

30. Ho, C., Advances in central receivers for concentrating solar applications. Solar Energy, 2017. 152: p. 38.

31. Kerr, P., et al., Implementing radical innovation in renewable energy experience curves. Energies, 2021.14 : p. 2364.

32. Mehos, M., et al., Concentrating solar power Gen3 demonstration roadmap. 2017, National Renewable Energy Laboratory (NREL): Golden, CO.

33. Kiefer, C.P. and P. del Río, Analysing the barriers and drivers to concentrating solar power in the European Union. Policy implications. Journal of Cleaner Production, 2020. 251: p. 119400.

34. Murphy, C.A., A. Schleifer, and K. Eurek, A taxonomy of systems that combine utility-scale renewable energy and energy storage technologies. Renewable and Sustainable Energy Reviews, 2021. 139: p. 110711.

35. Cardemil, J.M., et al., Integration schemes for hybrid and polygeneration concentrated solar power plants. WIREs Energy and Environment, 2021. n/a(n/a): p. e412.

36. Ju, X., et al., A review on the development of photovoltaic/concentrated solar power (PV-CSP) hybrid systems. Solar Energy Materials and Solar Cells, 2017. 161: p. 305-327.

37. Thonig, R. and J. Lilliestam, Concentrating Solar Technology Policy Should Encourage High Temperatures and Modularity to Enable Spillovers. AIP Conference Proceedings, in review.

38. Kraemer, S. Can a new kind of CSP be a game changer? 2021 2021.08.23]; Available from: https://bit.ly/3ntrRLt.

39. Ho, C., et al., Overview and design basis for the Gen 3 particle pilot plant (G3P3). AIP Conference Proceedings, 2020. 2303: p. 030020.

40. Grubb, M., Planetary economics. 2014, Routledge: New York.

41. Nemet, G.F., V. Zipperer, and M. Kraus, The valley of death, the technology pork barrel, and public support for large demonstration projects. Energy Policy, 2018. 119: p. 154-167. 
42. Nemet, G.F., Technological Improvements in Solar Thermal Electricity in the United States and the Role of Public Policy, in Energy Technology Innovation: Learning from Historical Successes and Failures, A. Grubler and C. Wilson, Editors. 2013, Cambridge University Press: Cambridge. p. 165-177.

43. de la Tour, A., M. Glachant, and Y. Ménière, Economic analysis of the CSP industry. 2010, Mines ParisTech.

44. Geyer, M., et al., EuroTrough - parabolic trough collector developed for cost efficient solar power generation. SolarPACES 2002 conference, 2003: p. 1-7.

45. Relloso, S. and Y. Gutiérrez, SENER molten salt tower technology: Ouarzazate Noor III case. AIP Conference Proceedings, 2016. 1850: p. 030041.

46. Montero, C., et al., CRS Sales: Abengoa's molten salt pilot power tower plant celebrates one year of uninterrupted operation. Energy Procedia, 2014. 49: p. 488-497.

47. Mir-Artigues, P., P. del Río, and N. Caldés, The economics and policy of concentrating solar power. 2019 , Cham: Springer.

48. Lilliestam, J., et al., Empirically observed learning rates for concentrating solar power and their responses to regime change. Nature Energy, 2017. 2: p. 17094.

49. Brutschin, E., A. Cherp, and J. Jewell, Failing the formative phase: the global diffusion of nuclear power is limited by national markets. Energy Research \& Social Science, 2021. 80: p. 102221.

50. McPherson, M., M. Mehos, and P. Denholm, Leveraging concentrating solar power plant dispatchability: A review of the impacts of global market structures and policy. Energy Policy, 2020. 139: p. 111335.

51. Lilliestam, J., et al., Policies to keep and expand the option of concentrating solar power for dispatchable renewable electricity. Energy Policy, 2018. 116: p. 193-197.

52. del Río, P. and P. Mir-Artigues, Designing auctions for concentrating solar power. Energy for Sustainable Development, 2019. 48: p. 67-81.

53. Mehos, M., et al., Concentrating Solar Power Best Practices Study. 2020: United States.

54. Bousselamti, L., W. Ahouar, and M. Cherkaoui, Multi-objective optimization of PV-CSP system in different dispatch strategies, case of study: Midelt city. Journal of Renewable and Sustainable Energy, 2021. 13(1): p. 013701.

55. Rosenstiel, A., et al., Electrochemical Hydrogen Production Powered by PV/CSP Hybrid Power Plants: A Modelling Approach for Cost Optimal System Design. Energies, 2021. 14(12).

56. Schmitt, T., (Why) did Desertec fail? Local Environment, 2018. 23(7): p. 747-776. 